\title{
FUNÇÃO: UMA LINGUAGEM DE FÁCIL COMPREENSÃO E A UTILIZAÇÃO DE SOFTWARES
}

\author{
Sônia Cristina da Cruz Mendes - Mestranda em Educação \\ Matemática -USS - Vassouras - soniaccm@click21.com.br
}

\section{Resumo}

Este artigo relata uma experiência de utilização do laboratório de informática para o ensino de matemática no conteúdo específico de funções. O objetivo principal deste artigo é relatar a possibilidade do ensino/aprendizagem de funções através da observação e descoberta intuitiva, permitida pelo o uso dos softwares. O trabalho foi realizado com a utilização do software graphmatica. É fundamental atentar para a importância da inserção dos professores nos ambientes informatizados, como forma de uma nova ferramenta para facilitar o ensino.

Palavras-chave: informática, função, graphmatica.

\section{Abstract}

This article describes an experience of using the computer lab for teaching mathematics in content-specific functions. The aim of this paper is to report the possibility of teaching / learning function through observation and intuitive discovery, allowed by the use of software. The study was conducted using the software Graphmatica. It is essential to pay attention to the importance of teachers in the integration of computing environments, such as a new tool to facilitate teaching.

Keywords: computing, function, Graphmatica 


\section{Introdução}

A compreensão do conceito de função e sua relação com o cotidiano são fundamentais para que ocorra o ensino/aprendizagem do referido conteúdo.

A grande dificuldade da matemática, de um modo geral, está relacionada à distância entre as experiências vividas e os conteúdos. Cada vez mais, busca-se mudar esse quadro, inclusive com elaboração de livros didáticos que contribuam nesses aspectos.

"É necessário que os alunos captem logo e com toda clareza a noção de função para o que devem construir e estudar eles mesmos exemplos variados em domínios muito diferentes, tais como a álgebra, a aritmética, a geometria, a física, a vide diária, etc". (Gustavo Choquet).

É notório que o conceito de função é de grande relevância para matemática e de aplicação nos vários ramos do conhecimento.

A palavra relação está constantemente presente no cotidiano, como por exemplo: relacionar objetos a uma determinada pessoa, relacionar as notas de um aluno, e até os relacionamentos entre pessoas.

Desde a infância o indivíduo exercita a correspondência, ou seja, a relação de objetos, números, pessoas e etc.

É preciso mostrar para os alunos que a função, nada mais é que um tipo especial de relação entre dois conjuntos.

"Toda vez que se traduz através de uma expressão matemática, o relacionamento entre o comportamento do que se está observando e os fatores que o condicionam, pode-se dizer que se venceu a etapa principal do estudo em questão. Passamos a dominar a interpretação desse relacionamento de forma objetiva, porque podemos representá-lo de uma forma sucinta". (Moema Sá Carvalho et all , p.83).

A própria construção dos conjuntos numéricos pode ser explicada através de uma função. 


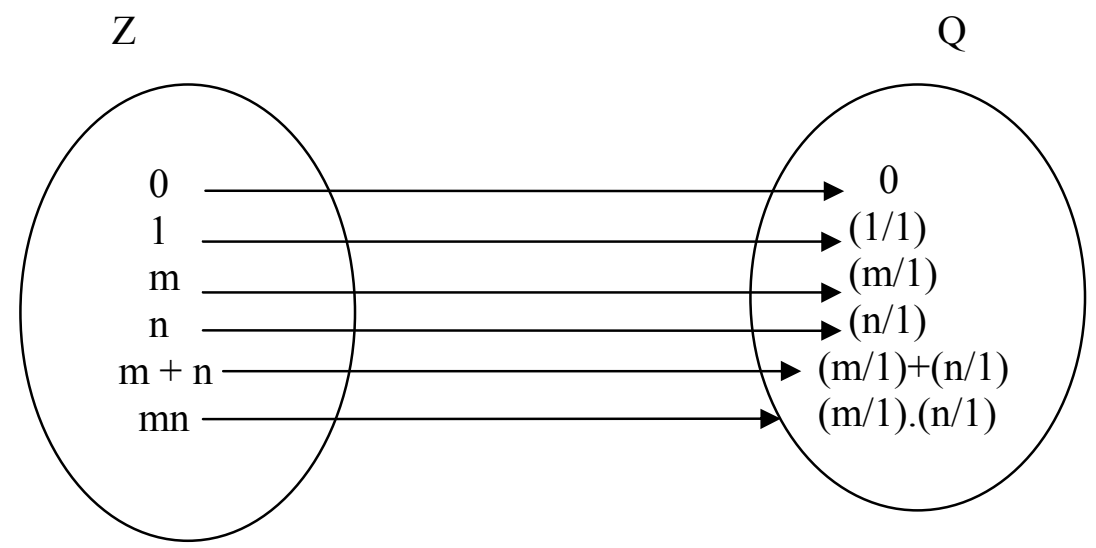

O simples ato de abastecer um automóvel pode ser traduzido em uma tabela que representa uma função.

$\begin{array}{cc}\text { LITROS } & \text { PREÇO PAGO } \\ 1 & 2,70 \\ 2 & 5,40 \\ 3 & 8,10\end{array}$

Fórmula matemática $\mathrm{y}=2,70 \mathrm{x}$

Conjuntos, relações, funções, equações, conceitos aparentemente desconhecidos, mas que são praticados diariamente e que a matemática apenas traduz através de suas fórmulas e observa os acontecimentos com suas respectivas variações.

\section{A contribuição dos softwares no ensino de função}

Os softwares por si só não acrescentam conhecimentos, é preciso formular os questionamentos e os exercícios a serem desenvolvidos com os softwares, delimitando os respectivos objetivos.

Um argumento favorável para o uso dos softwares é o de atrair a atenção dos alunos para o novo, ao mesmo tempo, exercendo apreensão do conhecimento. Aulas atrativas com diferencial da sala de aula "quadro e giz".

"Muitos advogam o uso do computador devido à motivação que ele traria à sala de aula. Devido às cores ao dinamismo e à importância dada aos computadores do ponto de vista social, o seu uso na educação poderia ser a solução para falta de motivação dos alunos". (Borba e Penteado, p. 15).

O professor não deve se limitar a uma única metodologia precisa ser criativo e apresentar diversidades, permitindo o melhor desenvolvimento do raciocínio lógico e contribuindo com aulas inovadoras e motivadoras, que permitam ao aluno investigar e realizar novas descobertas. 
Atualmente, muitas escolas possuem sala de informática, equipada com vários computadores, com o apoio dos OTs (orientadores tecnológicos).

Nessa perspectiva, os recursos tecnológicos estão se tornando presentes nas escolas públicas e privadas, trazendo benefícios. Falta o exercício do consumo da tecnologia.

O recurso por si só não resolve é necessário uma mudança de hábito para apreensão de novas práticas de ensino.

"Avanços na passagem do discurso curricular para a prática efetiva em sala de aula são pequenos e incipientes".(Frota e Borges, 2004).

Especificamente para o ensino de função, o professor poderá iniciar enfatizando as situações cotidianas associando ao aspecto conceitual e posteriormente utilizar o auxilio dos recursos tecnológicos.

Compreendido intuitivamente o conceito de função, será escolhido um software como: graphmatica, winplot, Excel, fun e outros apropriados para o ensino de função. A fim de traçar e observar os respectivos gráficos das funções.

Segundo alguns autores (Borba e Confrey, 1996; Kaput, 1987; Eisenberg e Dreyfus, 1991; Goldenberg e Kliman, 1990) questiona-se uma abordagem voltada para as representações múltiplas.

Em geral, os softwares facilitam essa visualização das várias representações de uma função de forma rápida. Como é possível observar na figura 1. do software Graphmatica.

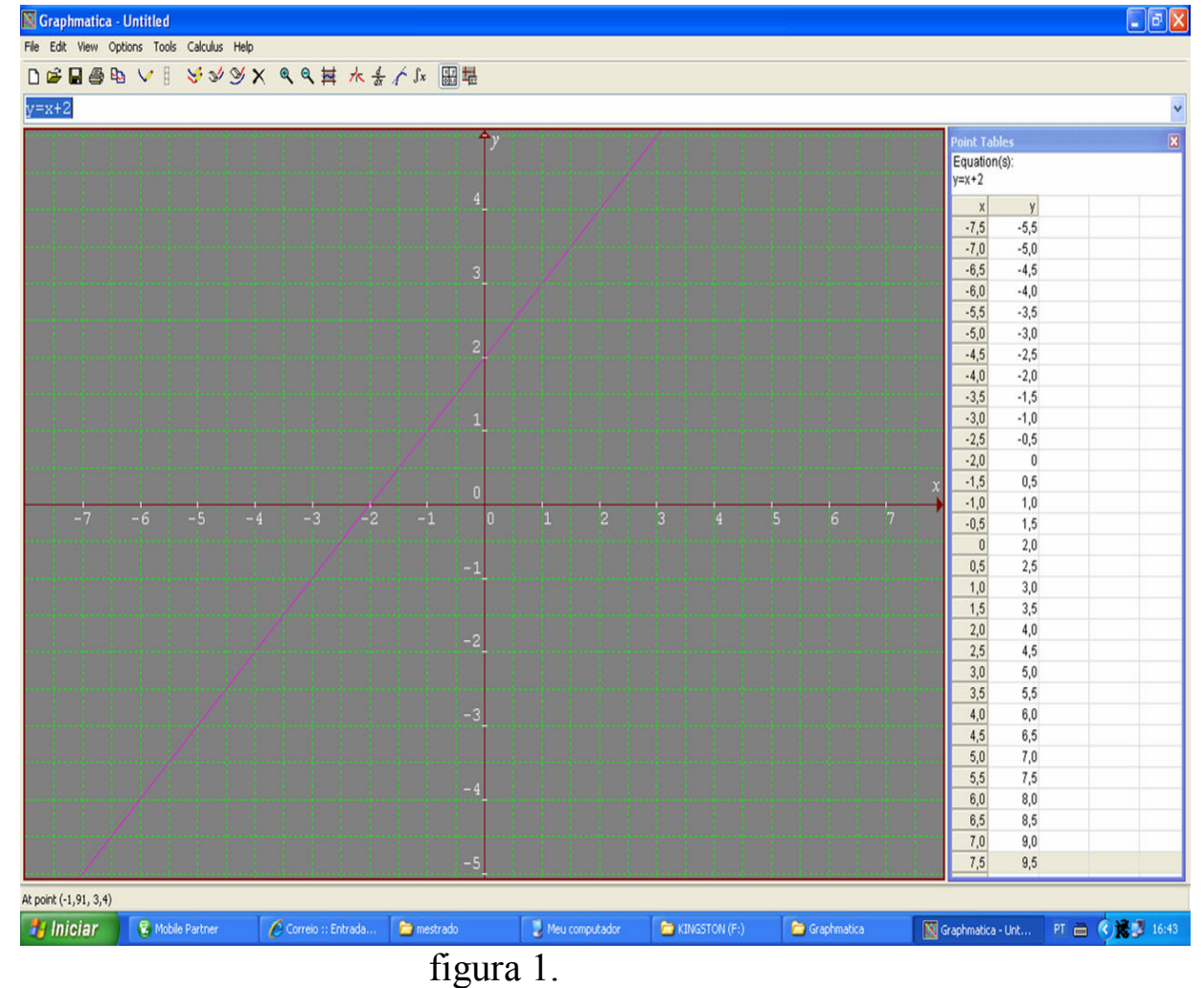

Podemos observar as representações algébricas, gráficas e tabelas. 


\section{Da teoria à prática}

Com o objetivo de investigar a melhor aprendizagem com a utilização das tecnologias e demonstrar a facilidade de realizar novas descobertas através da observação, foi desenvolvida uma pesquisa com alunos do $1^{\mathrm{o}}$ ano do ensino médio, utilizando o software Graphmatica.

Primeiramente, foi realizada uma aula expositiva na sala de vídeo, com retroprojetor, apresentando o funcionamento e manuseio do software Graphmatica, esclarecendo as possíveis dúvidas.

Através da observação dos gráficos plotados os alunos por si só perceberam as diferenças e alterações dos gráficos no caso de funções com coeficientes angulares positivos e a inversão do posicionamento da reta no caso de negativos. Além da possibilidade de verificação dos zeros da função. A cada percepção os alunos faziam as devidas anotações para serem debatidas e questionadas.

$\mathrm{O}$ uso do software permite uma melhor visualização, consequentemente melhor formulação dos conceitos.

Essas observações perderiam o foco principal se fosse utilizado papel quadriculado para efetuar o desenho dos gráficos, pois se tornaria demorado e exaustivo o trabalho.

\section{Referências Bibliográficas}

CARVALHO, Moema Sá; LOPES, Maria Laura M. Leite; SOUZA, José Carlos de Mello e. Fundamentação da Matemática Elementar.. Editora Campus. 1984.

MORAN, José Manuel. A educação que desejamos: Novos desafios e como chegar lá. $4^{\mathrm{a}}$ ed. Papirus, 2009.

Borba, Marcelo de Carvalho. Penteado, Miriam Godoy. Informática e Educação Matemática. 4. ed. - Belo Horizonte: Autêntica Editora, 2010. 104p.

Ubiratan D'Ambrósio, Informática, ciências e matemática,Proinfo: Programa Nacional de Informática na Educação (http://www.proinfo.mec.gov.br/site/biblioteca.php), Ministério da Educação e Cultura - MEC, 2000. 